Revue des patrimoines

\title{
Hommage à Gilles Chomer : L'Enfant Jésus retrouvé au Temple, un nouveau Stella dans les Pyrénées
}

Pierre Curie et Bertrand Ducourau

\section{OpenEdition}

Journals

Édition électronique

URL : http://journals.openedition.org/insitu/1975

DOI : 10.4000/insitu.1975

ISSN : 1630-7305

Éditeur

Ministère de la culture

Référence électronique

Pierre Curie et Bertrand Ducourau, « Hommage à Gilles Chomer : L'Enfant Jésus retrouvé au Temple, un nouveau Stella dans les Pyrénées », In Situ [En ligne], 3 | 2003, mis en ligne le 23 avril 2012,

consulté le 01 mai 2019. URL : http://journals.openedition.org/insitu/1975; DOI : 10.4000/insitu.1975

Ce document a été généré automatiquement le 1 mai 2019.

\section{(c) $(1) \odot$}

In Situ Revues des patrimoines est mis à disposition selon les termes de la licence Creative Commons Attribution - Pas d'Utilisation Commerciale - Pas de Modification 4.0 International. 


\section{Hommage à Gilles Chomer : L'Enfant Jésus retrouvé au Temple, un nouveau Stella dans les Pyrénées}

Pierre Curie et Bertrand Ducourau

Figure 1

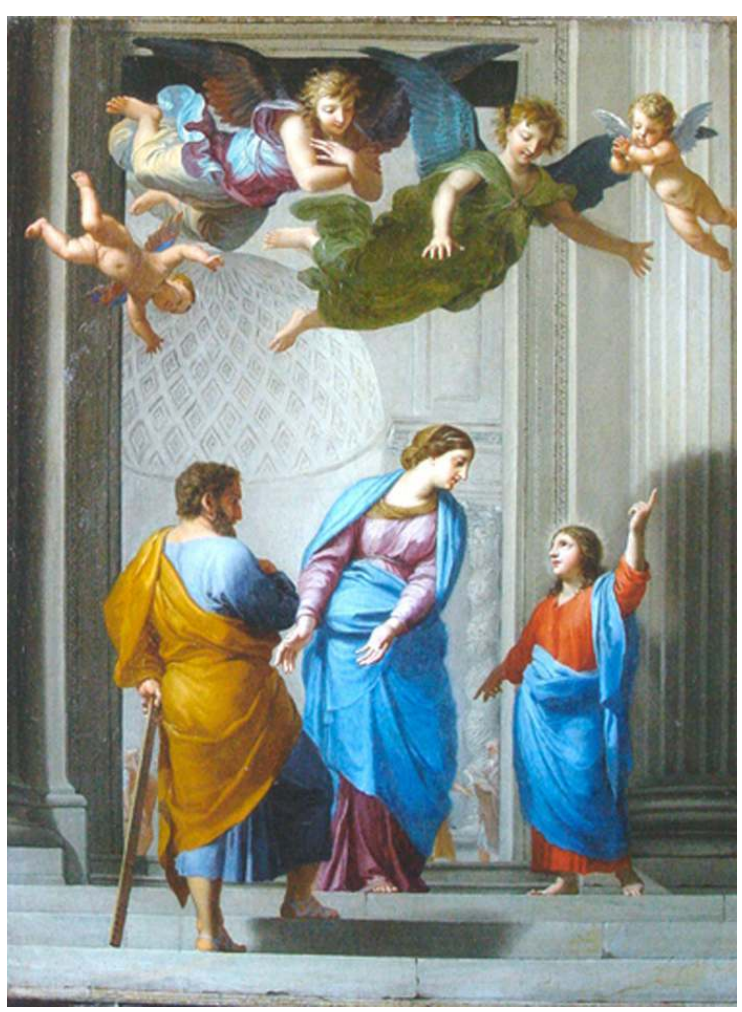

Jacques Stella, L'ENFANT Jésus Retrouvé AU TEMPLE, Saint-Béat, trésor de l'église (dépôt de la municipalité de Fos)

Phot. André Mielniczek (C) Ministère de la culture, DRAC Midi-Pyrénées, 2000 
1 La redécouverte de cette toile séduisante ${ }^{1}$, mise en dépôt dans le trésor de l'église de Saint-Béat (Haute-Garonne) par la municipalité de Fos, ajoute une nouvelle version à un groupe de peintures dérivant toutes du chef-d'œuvre de Jacques Stella (1596-1657), peint vers 1642 pour le noviciat des jésuites du Faubourg Saint-Germain à Paris.

2 La présence de cette œuvre dans l'église de Fos, petit village de fond de vallée pyrénéenne, est d'autant plus remarquable du fait de la relative rareté, dans les édifices pyrénéens de ce département, de peintures sur toile ${ }^{2}$. Cette rareté ainsi que sa très grande qualité lui ont valu le classement dès le début $\mathrm{du} \mathrm{XX}^{\mathrm{e}}$ siècle (sous le nom de Le Sueur). La commune, consciente de sa valeur, mais ne disposant pas pour l'instant d'un local pouvant garantir sa sécurité, a consenti à la mettre en dépôt au trésor de l'église de Saint-Béat.

3 La personnalité de Stella est désormais bien connue, depuis les travaux de Gilles Chomer notamment $^{3}$ : sa place dans l'atticisme parisien et son rôle artistique à Lyon en font l'un des protagonistes majeurs du classicisme français.

4 A propos de la composition qui nous occupe ici, récemment étudiée sous l'angle de l'iconographie ${ }^{4}$, tout a été dit sur les quatre exemplaires connus jusqu'alors, conservés à Notre-Dame des Andelys (Eure) ${ }^{5}$, à la basilique Saint-Liduina de Schiedam (Pays-Bas) ${ }^{6}$, à Lyon, au musée des Beaux-Arts ${ }^{7}$ ainsi qu'à l'église Saint-Ayoul de Provins (Seine-etMarne $)^{8}$. A ces tableaux s'ajoutent plusieurs dessins ${ }^{9}$. C'est dire assez le succès de l'œuvre et sa place importante dans le corpus de l'artiste.

Figure 2

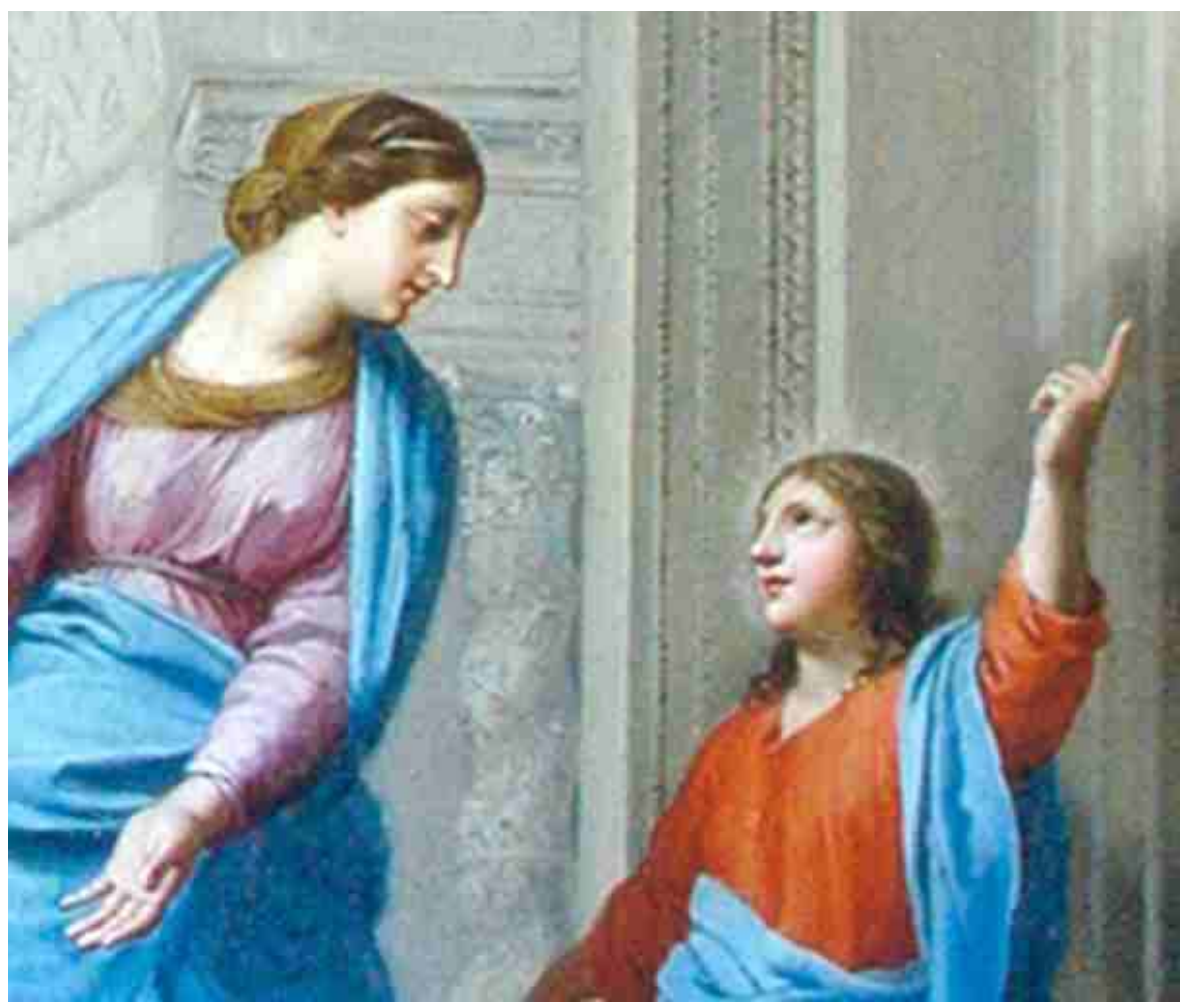

Jacques Stella, L'ENFANT JÉsus RETrouvé Au TEMPLE (détail), Saint-Béat, trésor de l'église (dépôt de la municipalité de Fos)

Phot. André Mielniczek (c) Ministère de la culture, DRAC Midi-Pyrénées, 2000 
Les différents tableaux présentent tous des variantes, notamment dans l'architecture de l'arrière-plan, comme si l'artiste s'était plu à décliner son invention non seulement en modifiant les supports, les dimensions et les techniques employées, mais aussi en retravaillant subtilement l'ambiance de la scène par le traitement de l'espace du Temple. Cependant, la permanence du style de Stella de l'une à l'autre version s'établit aisément dans l'éclairage cristallin et dans une monumentalité de conception qui, comme chez Le Sueur, n'exclut pas la délicatesse.

Bien qu'elle soit inversée et simplifiée par rapport au prototype des Andelys, la composition de Saint-Béat est certainement une réplique de la main même de Stella ${ }^{10}$ : le fond d'architecture, avec sa belle abside à caissons, et le groupe des anges, si typiques du peintre, ne se retrouvent dans aucune des autres «rédactions» du thème. Malheureusement, à ce stade des recherches, aucune provenance ancienne n'a pu être établie avec certitude pour cette œuvre datable des années 1645-1650. Elle aurait appartenu à la famille de Lassus, originaire de la commune proche de Montrejeau, dont l'un des membres était chambellan à la cour de Louis XIV. Une suite de mariages et de successions, qui ne sont pas à ce jour bien connus, aurait amené au don de la toile à l'église de Fos, au XIX'e siècle.

7 Il est heureux que de modestes églises, d'humbles chapelles et de petits trésors ou musées d'art sacré, si indispensables à la conservation de la mémoire des lieux, puissent réserver de telles - bonnes - surprises pour les historiens de l'art «savant ». Cette découverte prouve en tout cas, si cela était nécessaire, que le patrimoine français reste encore largement à explorer.

\section{NOTES}

1. Huile sur toile, $88 \times 71 \mathrm{~cm}$ (cadre du XIX ${ }^{\mathrm{e}}$ siècle), classée au titre des Monuments historiques le 5 novembre 1912. Restaurée en 2001 par André Mielniczek: support: désentoilage; doublage. Couche picturale: nettoyage, enlèvement des retouches anciennes assombries, réintégrations picturales ponctuelles.

2. Si la statuaire et les retables pyrénéens ont été largement étudiés, et par là même considérés comme représentatifs du patrimoine pyrénéen, en revanche la peinture de chevalet de ces édifices reste relativement méconnue.

3. Gilles Chomer, décédé il y a peu, préparait une exposition Stella avec le musée des Beaux-Arts de Lyon.

4. Henin, Emmanuelle. L'Enfant Jésus au milieu des docteurs : une image de la parabole au XVII e siècle. A propos d'une ekphrasis jésuite d'un tableau de Stella. Gazette des Beaux-Arts, juilletaouicirc;t 2000. P. 31-48.

5. Huile sur toile, $380 \times 200 \mathrm{~cm}$; il s'agit du tableau anciennement au noviciat des jésuites de Paris, voir Grand siècle : peintures françaises du XVII ${ }^{\mathrm{e}}$ siècle dans les collections publiques françaises, cat. exp., Montréal, Rennes, Montpellier. RMN, 1993. P. 242, n 78 [notice par M. Hilaire] et Le Dieu caché. Les peintres du grand siècle et la vision de Dieu, cat. exp. Rome, Académie de France, 2000-2001. P. 127-130, nº 18 [notice par E. Coquery]. 
6. Huile sur cuivre, $47,3 \times 35,2 \mathrm{~cm}$, signée et datée 1649 ; voir Huys Janssen, Paul. A newly discovered painting by Jacques Stella in Holland. The Burlington Magazine, novembre 1996. P. 750-751.

7. Huile sur bois, $65,5 \times 54,5 \mathrm{~cm}$, signée et datée 1645 ; voir Rosenberg, Pierre. Tableaux français du XVII ${ }^{\mathrm{e}}$ siècle. Revue du Louvre et des musées de France, 1979, n 5-6. p. 401-407.

8. Voir Kerspern, Sylvain. "Jésus retrouvé par ses parents dans le Temple" (1654) par Jacques Stella (Provins, église Saint-Ayoul). Gazette des Beaux-Arts, juillet-août 1989, n 1446-1447. P. $1-10$.

9. Conservés notamment en collection particulière, à l'Art Gallery of Ontario de Toronto, au Museum Kunsthaus de Worms, etc.

10. Consulté sur le tableau en 2000, Alain Mérot a également rapproché le tableau de Stella.

INDEX

Mots-clés : peinture religieuse, iconographie, Jacques Stella

\section{AUTEURS}

\section{PIERRE CURIE}

Conservateur du patrimoine, Sous-direction des études, de la documentation et de l'Inventaire. pierre.curie@culture.gouv.fr

\section{BERTRAND DUCOURAU}

Conservateur du patrimoine, Conservation régionale des monuments historiques, Direction régionale des affaires culturelles de Midi-Pyrénées, bertrand.ducourau@culture.gouv.fr 